\title{
Impurity profiling method development and validation of metformin hydrochloride and teneligliptin hydrobromide hydrate in their combination tablet dosage form by using RP-HPLC with UV/PDA detector
}

\author{
B. D. Musmade ${ }^{1}$, M. L. Baraskar', V. N. Ghodke', S. G. Bhope', S. Padmanabhan¹ and K. S. Lohar²*
}

\begin{abstract}
Background: An accurate, precise and robust analytical method was developed for the impurity profiling in the metformin hydrochloride and teneligliptin hydrobromide hydrate tablet. The gradient was optimized for better separation of impurities by using BDS Hypersil C18 $250 \times 4.6 \mathrm{~mm}, 5 \mu$ column operated at $35^{\circ} \mathrm{C}$. The octane sulfonic acid and phosphate buffer with triethylamine at $\mathrm{pH} 3.0$ were used as mobile phase $\mathrm{A}$, and acetonitrile was used as mobile phase B. The mobile phase was pumped at $1.0 \mathrm{~mL} / \mathrm{min}$. The gradient was optimized for better resolution, and the chromatogram was monitored at $210 \mathrm{~nm}$.

Results: The \% recovery of teneligliptin and metformin HCL observed was above $90 \%$ from LOQ level to 150\%. The correlation coefficient $r^{2}$ was 0.999 for metformin $\mathrm{HCl}$, teneligliptin, melamine, cyanocobalamin, teneligliptin impurity A and 0.998 for teneligliptin impurity B. The method was found unaffected by change in method variance during the robustness study. During the stress study with acid, base, peroxide and temperature, maximum degradation was observed with peroxide indicating the sensitivity of the molecule toward oxidative stress.

Conclusions: The developed method is precise, accurate, robust and linear and hence can be routinely used for the related substance analysis of metformin hydrochloride and teneligliptin hydrobromide hydrate tablet in the quality control laboratory at manufacturing site during the commercial manufacturing.
\end{abstract}

Keywords: Metformin hydrochloride, Teneligliptin hydrobromide hydrate, Method validation, Impurity profiling

\section{Background}

Controlling the organic impurities in various pharmaceutical products/compositions is critical to maintain the purity of drugs which has direct impact on the safety and efficacy of drugs from the perspective of the patient. An accurate, sensitive and a robust stability indicating analytical method can help to monitor the drug stability

\footnotetext{
*Correspondence: Dr.kslohar@rediffmail.com

${ }^{2}$ Department of Chemistry, Shrikrishna Mahavidyalay Gunjoti, Gunjoti, Maharashtra 413606, India

Full list of author information is available at the end of the article
}

parameters and minimize production losses. The detection wavelength for detection of impurities of each drug, limit of detection and the label claim of each drug in the finished product are critical parameters during the development of such an analytical method.

\section{Metformin hydrochloride (MTF) and teneligliptin hydrobromide hydrate (TNG)}

The metformin hydrochloride and teneligliptin hydrobromide hydrate are a well-known rational combination used in the treatment of diabetes all over the world. This 
oral anti-hyperglycemic combination is a drug of choice worldwide to treat mild-to-moderate diabetic patients.

\section{Metformin hydrochloride (MTF)}

MTF (Fig. 1a) is a biguanide derivative used to lower the blood glucose concentration in patients with noninsulin-dependent diabetes mellitus [1]. Chemically, it is 1,1-dimethylbiguanide hydrochloride easily soluble in water, marginally soluble in ethanol and almost insoluble in acetone and methylene chloride [2].

\section{Teneligliptin hydrobromide hydrate (TNG)}

IUPAC name of TNG is [(2S,4S)-4-[4-(5-methyl-2-phenylpyrazol-3-yl)piperazin-1-yl]pyrrolidin-2-yl]-(1,3-thiazolidin-3-yl)methanone;hydrate;pentahydrobromide. TNG (Fig. 1b) is dipeptidyl peptidase-IV inhibitor (DPPIV), off white to cream colored powder [3]. It is a strong, modest and long-performing DPP-1V inhibitor [4]. The DPP-IV inhibitors are recently developed antidiabetic agents which have demonstrated promising results in modifying the glycemic control of diabetic patients with a minimum risk of hypoglycemia and weight gain [5].

During the literature review, we realized that many assay methods are reported for these two compounds. Some reported assay methods are based on UV-visible spectroscopy [6-8] technique. These methods being nonstability indicating and are no longer accepted by regulatory agencies. Some reported assay methods are by using high-performance thin-layer chromatographic (HPTLC) technique $[9,10]$. Since HPTLC method lacks sensitivity, hence it is not acceptable for quantification purpose. The reported HPLC stability indicating methods [11-19] is either for the assay of MTF and TNG individually or for combination products with various other antidiabetic molecules. We also found some methods like individual impurity profiling methods of MTF and TNG [20-23], degradation of linagliptin in the presence of metformin $\mathrm{HCL}$, impurity of glimepiride and metformin $\mathrm{HCl}[24$, 25], while simultaneous estimation of omarigliptin, trelagliptin and alogliptin from rat plasma [26]. There is no any reported method for the impurity testing of MTF and TNG combined dosage form. Further, it is observed that there is a significant difference in the dose of MTF (500/1000 mg/tablet) and TNG (20 mg/tablet) when available as a combination product. In the present work, an attempt has been made to develop a precise, accurate and stability indicating analytical HPLC method for the quantitation of organic impurities from MTF and TNG from the combination product. The developed method was validated as per ICH Q1 (R2) guideline $[27,28]$. The developed method being robust and simple can be used in the routine impurity testing studies in the quality control laboratories of pharmaceutical companies engaged in this drug combination.

\section{Methods}

Pure compounds

The MTF (99.8\% purity) and TNG (99.6\% purity) were used for preparation of respective standards for the development and validation studies. The cyanoguanidine and melamine impurities of MTF and TNG impurities (impurity A, impurity B) were purchased from Chromachemie.

\section{Formulation used}

The In-house (Sava Healthcare limited, R\&D, Pune India) formulated sample and placebo were used during the method development and validation study.

\section{Chemicals, reagents and equipment}

HPLC grade methanol and acetonitrile (Rankem, Mumbai, India), potassium dihydrogen phosphate (Rankem, Mumbai, India), octane sulfonic acid sodium salt (Finar) and orthophosphoric acid (Rankem) were used for diluent and mobile phase preparation. The calibrated seven compact $\mathrm{pH}$ meter (Mettler Toledo) was used for $\mathrm{pH}$ measurement. The separation of all the impurities was achieved on a BDS Hypersil C18, $250 \times 4.6 \mathrm{~mm}, 5 \mu$

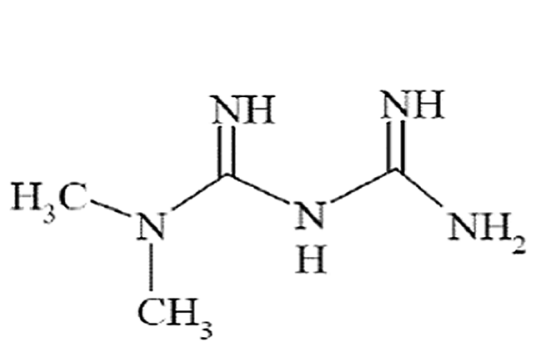

(a)

$\mathrm{HCl}$

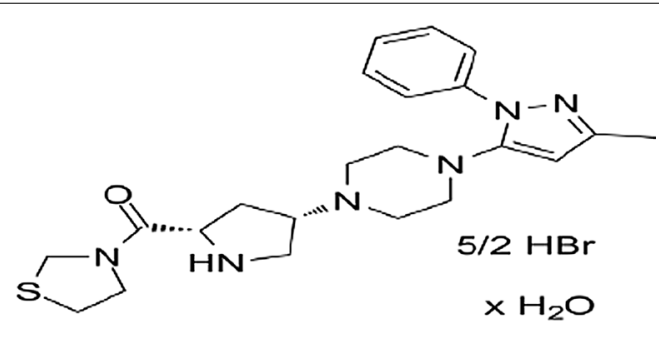

(b)

Fig. 1 Structure of a metformin $\mathrm{HCl}$, b teneligliptin hydrobromide hydrate 
Table 1 Chromatographic conditions

\begin{tabular}{ll}
\hline HPLC parameters & Conditions \\
\hline HPLC column & BDS Hypersil C18, \\
Column temperature & $250 \times 4.5 \mathrm{~mm}, 5 \mu$ \\
Sample cooler temperature & $35{ }^{\circ} \mathrm{C}$ \\
Flow rate & $\mathrm{Ambient}$ \\
Injection volume & $1 \mathrm{~mL} / \mathrm{min}$ \\
Wavelength & $20 \mu \mathrm{L}$ \\
\hline
\end{tabular}

Table 2 Gradient program

\begin{tabular}{lll}
\hline Time in min & \% mobile phase A & $\begin{array}{l}\text { \% mobile } \\
\text { phase B }\end{array}$ \\
\hline 0.1 & 75 & 25 \\
10.0 & 70 & 30 \\
45.0 & 40 & 60 \\
55.0 & 40 & 60 \\
55.01 & 75 & 25 \\
65.0 & 75 & 25 \\
\hline
\end{tabular}

column (Thermo Scientific, UK). The complete development and validation study were performed by using LC$2010 C_{\mathrm{HT}}$, with VU-visible detector (Shimadzu, Japan) using liquid chromatographic system. Intermediate precision and selectivity study were performed on Alliance 2695 with PDA detector (Waters, USA).

\section{Mobile phase and diluent preparation}

$2.72 \mathrm{~g}$ of potassium dihydrogen phosphate and $1 \mathrm{~g}$ of octane sulfonic acid sodium salt were transferred to $1000 \mathrm{~mL}$ water containing $1 \mathrm{~mL}$ triethylamine and $10 \mathrm{~mL}$ methanol in the glass mobile phase bottle. The bottle was sonicated to mix for $5 \mathrm{~min}$ and dissolve the reagents completely. The $\mathrm{pH}$ was adjusted to 3.0 using orthophosphoric acid. The mobile phase was then filtered through $0.45 \mu \mathrm{m}$ filter to remove the dissolved gases and contaminants and further used as mobile phase A. The HPLC grade methanol was used as mobile phase $B$. The mixture of water and acetonitrile (80:20) was used as the diluent.

\section{Optimization of chromatographic conditions}

For optimum resolution, we tried Baker bond C18 (Make-Avantor), Symmetry C18 (Waters) and Inertsil ODS (GL, Lifesciences) columns. Maximum resolution between impurities and principle analyte peaks was achieved on BDS Hypersil C18, $250 \times 4.5 \mathrm{~mm}, 5 \mu$ column at $35^{\circ} \mathrm{C}$ with $1 \mathrm{~mL} / \mathrm{min}$ flow rate in gradient elution mode. The optimized chromatographic conditions are summarized in Tables 1 and 2.

\section{System suitability solution preparation}

\section{Preparation of solution A}

Accurately weighed $5 \mathrm{mg}$ each MTF working standard, melamine impurity and cyanoguanidine impurity was transferred into a $50-\mathrm{mL}$ volumetric flask. About $30 \mathrm{~mL}$ diluent was added, and the contents were sonicated to dissolve completely. The volume was made up to the mark with the diluent and sonicated for 5 min to mix, before use.

\section{Preparation of solution B}

Accurately weighed $4 \mathrm{mg}$ of each TNG working standard, impurity A and impurity B was transferred all of them into a $100-\mathrm{mL}$ volumetric flask. About $70 \mathrm{~mL}$ diluent was added and sonicated to dissolve the contents completely. The volume was made up to the mark with the diluent and sonicated for $5 \mathrm{~min}$ to $\mathrm{mix}$, prior to use.

Further, $5 \mathrm{~mL}$ of solution A and solution B was transferred in a $100-\mathrm{mL}$ volumetric flask and diluted with diluent up to the mark, mixed and used as a system suitability solution.

\section{Preparation of standard solution 1}

About $5 \mathrm{mg}$ of MTF working standard was transferred into a $50-\mathrm{mL}$ volumetric flask dissolved and diluted to volume with diluent (standard stock solution A). Accurately weighed $4 \mathrm{mg}$ of TNG working standard was transferred into a $100-\mathrm{mL}$ volumetric flask. About $70 \mathrm{~mL}$ of diluent was added and sonicated to dissolve completely. The volume was adjusted up to the mark with diluent and mixed properly (standard stock solution B).

Further $5 \mathrm{~mL}$ of each standard stock solutions $\mathrm{A}$ and $\mathrm{B}$ was transferred in a $100-\mathrm{mL}$ volumetric flask. The volume was adjusted up to the mark with diluent and used as a standard solution 1 . The standard solution 2 was similarly prepared for the calculation of similarity factor.

\section{Preparation of standard solution 2}

The standard solution 2 was prepared as per standard solution 1.

\section{Sample preparation}

Ten tablets of IH combination product were crushed to a fine powder. Powder equivalent to $500 \mathrm{mg}$ of MTF was accurately weighed and transferred into a $100-\mathrm{mL}$ volumetric flask. About $70 \mathrm{~mL}$ of the diluent was added, and the contents were sonicated for $20 \mathrm{~min}$. The volume was made up to the mark with the diluent and mixed well. 
The sample was filtered through $0.45 \mu \mathrm{m}$ filter and used for HPLC analysis.

\section{Placebo preparation}

Placebo powder was weighed equivalent to sample weight and further processed as per sample preparation.

\section{System suitability criteria}

For development of a robust analytical method, we have defined the system suitability parameters like resolution, capacity factor, signal-to-noise ratio, theoretical plates, etc. Considering the long run time and solution stability issue, similarity factor was estimated by injecting the two standard solutions (standard solutions 1 and 2). The limit of similarity factor was set at $95-105 \%$. The resolution between each impurity and principle analyte peak was set NLT 2, the theoretical plate limit was kept at NLT 2000, and tailing factor limit was set NMT 2.0 as per USP system suitability criteria.

\section{Impurity calculation}

All the known impurities eluted in the sample chromatogram were calculated against the respective principle analyte peak in the standard solution 1 . The quantification of the unknown degradants peaks was done by degrading the individual API and specifying the relative retention time with respect to the principle analyte peak. The unknown impurities were calculated against the analyte having a low concentration (TNG) in the combination product.

\section{Method validation}

The developed method was validated as per ICH Q2 guidelines. The developed HPLC method was validated in terms of the following parameters: system suitability, specificity (selectivity and forced degradation), sensitivity (LOD and LOQ), linearity, precision, accuracy, filter study, stability of analytical solutions and robustness studies.

\section{Accuracy}

Accuracy study was carried out by spiking all the known impurities as well as MTF and TNG working standard at LOQ level, 50\%, 100\% and 150\% level of impurity limit in the placebo. Six preparations at LOQ level and three preparations each at 50\%, 100\% and $150 \%$ level were injected into the system. The $\%$ recovered amount was calculated for each known impurity, and principle analyte peak against the spiked amount was assessed. The limit of recovery was set at $80 \%$ to $120 \%$ at LOQ level and $85 \%$ to $115 \%$ at $50 \%$ to $150 \%$ level.

\section{Precision}

Separately prepared standard solutions 1 and 2 were injected into the HPLC system. The \% similarity factor was calculated for standard solutions 1 and 2 and monitored as per system suitability criteria. The \% similarity factor limit was set at $95-105 \%$ for MTF and TNG.

\section{Method precision}

Six sample solutions were prepared as described in the method and injected into the HPLC system. The \% RSD was calculated for all the known impurities, individual unspecified impurity and total impurities. The \% RSD limit was set at NMT $15 \%$.

\section{Intermediate precision}

Intermediate precision study was carried out by changing the analyst and HPLC system on different days. All the samples were prepared as per the method of analysis and injected into the HPLC system. The \% RSD was calculated for all the known impurities, individual unspecified impurity and total impurities.

\section{Specificity}

To prove the specificity of the developed method, the diluent as a blank solution, placebo solution, cyanoguanidine impurity solution, melamine impurity solution, TNG impurity A solution, TNG impurity B solution, MTF and TNG standard solutions were injected separately. The sample solution and impurity spiked solutions were prepared and injected into the HPLC system. The response of the individual analytes and peak purity was recorded by using the PDA (photodiode array) detector.

\section{Forced degradation study}

Forced degradation study of sample and placebo was carried out to prove the selectivity of the method and to evaluate the stability indicating nature of the method. Sample and placebo were exposed under relevant stress conditions like heat, acid, base and oxidation. These stressed samples were then analyzed by HPLC. The acid degradation was carried out by using $0.5 \mathrm{~N}$ hydrochloric acid for $2 \mathrm{~h}$ at $60{ }^{\circ} \mathrm{C}$ and alkali degradation by using $1 \mathrm{~N}$ sodium hydroxide for $5 \mathrm{~h}$ at room temperature. For thermal degradation, the sample and placebo were kept at $80^{\circ} \mathrm{C}$ for 2 days. The oxidative stress study was carried out by using $0.3 \%$ hydrogen peroxide for $12 \mathrm{~h}$. The photolytic degradation was carried out by exposing the drug sample for not less than 1.2 million lux h at $200 \mathrm{Wh} / \mathrm{sq}$. 
meter near ultraviolet energy by using the Sun test apparatus (Atlas, Germany).

\section{LOD and LOQ determination}

Series of known impurity solutions were prepared over a range starting from 1 to $50 \%$ of the working concentration and injected in triplicates. The linearity graph was plotted for average area at each level against the concentration in PPM. The correlation coefficient, slope and intercept were determined for each known impurity.

\section{Precision at LOQ Level}

Six solutions were prepared by spiking the MTF and TNG working standard along with all the known impurities at LOQ level in the placebo. The \% RSD of peak area and $\%$ results were calculated.

\section{Linearity}

The samples containing all the known impurities along with MTF and TNG working standard solutions were prepared from $150 \%$ to LOQ level $(150 \%, 120 \%, 100 \%$, $80 \%, 50 \%, 20 \%$ and LOQ) and injected in triplicate. The linearity graph was plotted for average area of individual analyte against the concentration in $\mu \mathrm{g} / \mathrm{mL}$ at each level. The correlation coefficient, slope and intercept were calculated.

\section{Range}

The range of concentration of analyte and impurity solutions was determined by evaluating the area under the curve and concentration for linear response.

\section{Stability of analytical solutions}

The MTF and TNG working standard solution and the impurity spiked sample solution were prepared. The solutions were stored at room temperature and evaluated against the freshly prepared standard solution on day 0 , day 1 , day 2 and day 3 . The $\%$ known impurity and total impurity were calculated for the stored samples at each time point and compared against results of freshly prepared sample.

\section{Filter validation study}

Filter validation study was conducted to prove the compatibility of the molecule and the impurities with the filter used during the sample and standard preparation. Sometimes the analyte may get adsorbed on the filter paper resulting in inconsistent results. The study was conducted by filtering the sample solution through filters like Nylon filter (MDI, India) and PVDF (Merck Millipore, Germany) filter having $0.45 \mu$ porosity and discarding the initial $2 \mathrm{~mL}, 3 \mathrm{~mL}$ and $5 \mathrm{~mL}$ of filtrate to optimize the sample filtration study for precise and accurate results.

\section{Robustness}

This study was conducted by intentionally altering the critical method parameters like flow rate $( \pm 0.1 \mathrm{~mL})$, $\mathrm{pH}$ of mobile phase $( \pm 0.2)$, change in column temperature $\left( \pm 5^{\circ} \mathrm{C}\right)$, change in wavelength $( \pm 2 \mathrm{~nm})$ and change in gradient composition. The diluent, standard solution, sample solution and impurity spiked sample solution were injected to check the robustness of analytical method.

\section{Results}

The developed method was validated as per $\mathrm{ICH}$ guideline Q2B (R1).

\section{Accuracy}

The developed method was found capable to recover the contents accurately when spiked at $50 \%$ to $150 \%$ of the working concentration. The obtained results in $\%$ as well as $\mu \mathrm{g} / \mathrm{ml}$ are summarized in Tables 3 and 4 .

\section{Precision}

The $\%$ similarity factor for standard 1 and standard 2 was found between 95 and 105\% during the complete validation study.

\section{Method precision and intermediate precision}

The \% RSD of known impurities, single maximum and total impurities was found to be less than $15 \%$ from six

Table 3 Recovery study results in \% recovered

\begin{tabular}{lcccc}
\hline Analytes name & Recovery at LOQ & Recovery at 50\% & $\begin{array}{c}\text { Recovery at 100\% } \\
\text { Recovery } \\
\text { at 150\% }\end{array}$ \\
\hline Cyanoguanidine & 81.7 & 99.3 & 102.1 & 101.0 \\
Melamine & 105.2 & 101.5 & 101.5 & 92.1 \\
Metformin HCl & 98.2 & 92.8 & 99.4 & 92.2 \\
Teneligliptin & 90.8 & 98.0 & 102.6 & 98.9 \\
Teneligliptin Impurity A & 97.5 & 98.4 & 107.8 & 103.9 \\
Teneligliptin Impurity B & 97.1 & 99.6 & & \\
\hline
\end{tabular}


Table 4 Recovery study results in $\mu \mathrm{g} / \mathrm{mL}$

\begin{tabular}{|c|c|c|c|c|c|c|c|c|}
\hline \multirow[t]{2}{*}{ Analytes name } & \multicolumn{2}{|c|}{ Recovery in $\mu \mathrm{g} / \mathrm{mL}$ at LOQ } & \multicolumn{2}{|c|}{ Recovery in $\mu \mathrm{g} / \mathrm{mL}$ at $50 \%$} & \multicolumn{2}{|c|}{ Recovery in $\mu \mathrm{g} / \mathrm{mL}$ at $100 \%$} & \multicolumn{2}{|c|}{$\begin{array}{l}\text { Recovery in } \mu \mathrm{g} / \mathrm{mL} \text { at } \\
150 \%\end{array}$} \\
\hline & Added & Recovered & Added & Recovered & Added & Recovered & Added & Recovered \\
\hline CYN & 0.051 & 0.042 & 2.545 & 2.527 & 5.090 & 5.197 & 7.635 & 7.711 \\
\hline Melamine & 0.053 & 0.056 & 2.640 & 2.680 & 5.280 & 5.359 & 7.920 & 7.868 \\
\hline MTF HCl & 0.058 & 0.0565 & 2.875 & 2.668 & 5.750 & 5.296 & 8.625 & 7.952 \\
\hline TNG & 0.215 & 0.195 & 1.075 & 1.054 & 2.150 & 2.137 & 3.225 & 3.190 \\
\hline TNG Imp. A & 0.221 & 0.216 & 1.105 & 1.087 & 2.210 & 2.268 & 3.315 & 3.245 \\
\hline TNG Imp. B & 0.022 & 0.208 & 1.073 & 1.072 & 2.145 & 2.312 & 3.218 & 3.332 \\
\hline
\end{tabular}

Table 5 Method precision study

\begin{tabular}{lllllllll}
\hline S. no & API/impurity & Spl.1 & Spl.2 & Spl.3 & Spl.4 & Spl.5 & Spl.6 & \%RSD \\
\hline 1 & CYN & 0.015 & 0.014 & 0.015 & 0.013 & 0.015 & 0.014 & 5.7 \\
2 & Melamine & 0.003 & 0.004 & 0.004 & 0.004 & 0.004 & 0.004 & 10.6 \\
3 & TNG Impurity A & ND & ND & ND & ND & ND & ND & ND \\
4 & TNG Impurity B & ND & ND & ND & ND & ND & ND & ND \\
5 & Single maximp & 0.082 & 0.084 & 0.076 & 0.085 & 0.0128 & 0.100 & 6.4 \\
6 & Total impurities & 0.320 & 0.340 & 0.296 & 0.324 & 0.377 & 0.335 & 8.1 \\
\hline
\end{tabular}

Table 6 Intermediate precision study

\begin{tabular}{lllllllll}
\hline S. no & API/impurity & Spl.1 & Spl.2 & Spl.3 & Spl.4 & Spl.5 & Spl.6 & \%RSD \\
\hline 1 & CYN & 0.013 & 0.015 & 0.014 & 0.015 & 0.014 & 0.014 \\
2 & Melamine & 0.004 & 0.004 & 0.003 & 0.004 & 0.004 & 0.004 & 5.3 \\
3 & TNG Impurity A & ND & ND & ND & ND & ND & ND & ND \\
4 & TNG Impurity B & ND & ND & ND & ND & ND & ND & ND \\
5 & Single Mix. Imp & 0.089 & 0.086 & 0.084 & 0.078 & 0.082 & 0.091 \\
6 & Total impurities & 0.316 & 0.308 & 0.296 & 0.298 & 0.325 & 0.308 & 3.6 \\
\hline
\end{tabular}

sample preparations during the method and intermediate precision study. The data are reported in Tables 5 and 6.

\section{Specificity \\ Selectivity}

No interference was observed at the retention time of known impurities and principle analyte peaks from blank and placebo solution. All the peaks were properly resolved from each other. The representative chromatograms of blank, placebo, system suitability, standard and spike sample are shown in Fig. 2a-d, respectively.

\section{Forced degradation (FD) study}

During FD study, we observed no significant degradation in acid $(<1 \%)$, alkali $(3.5 \%)$, thermal $(1.9 \%)$ and photolytic $(<1 \%)$ conditions. Significant degradation
(11.6\%) was observed during oxidative stress. During FD study, we observed no any interfering peak at the retention time of principle analyte peak and known impurities. All the peaks were evaluated for peak purity index through PDA detector and found pure. This showed the stability indicating nature of the developed method.

\section{LOD and LOQ determination}

The LOD and LOQ values of MTF, CYN and melamine were found to be $0.37,0.33,0.30 \mu \mathrm{g} / \mathrm{mL}$ and $1.11,1.17$, and $0.92 \mu \mathrm{g} / \mathrm{mL}$, respectively. The LOD and LOQ values of TNG, TNG impurity A and TNG impurity B were found to be $0.14,0.11,0.11 \mu \mathrm{g} / \mathrm{mL}$ and $0.42,0.33$, $0.34 \mu \mathrm{g} / \mathrm{mL}$, respectively. 


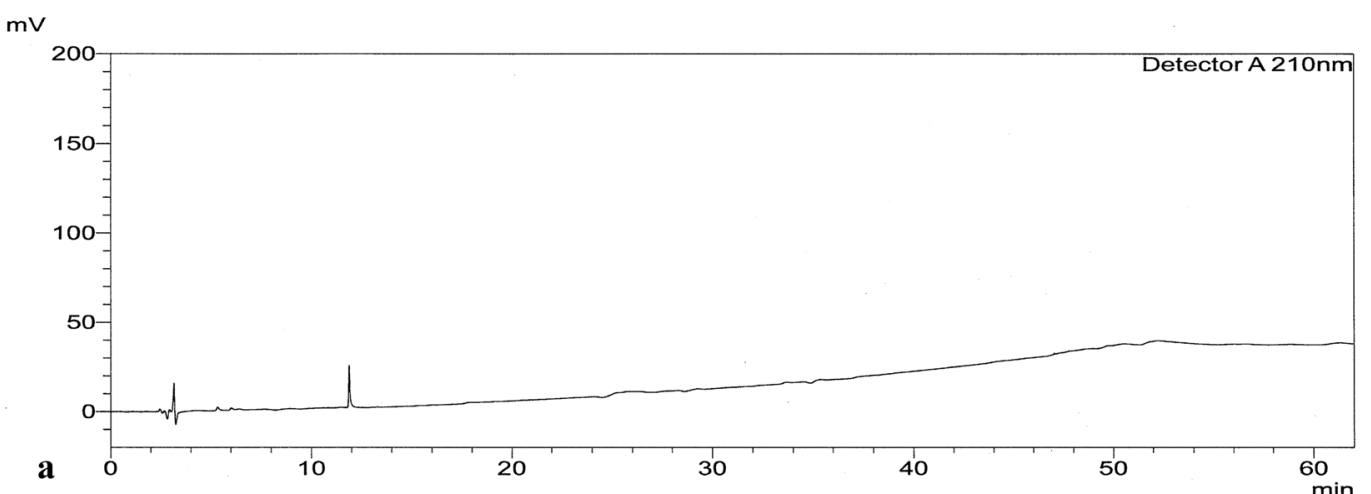

$\mathrm{mV}$

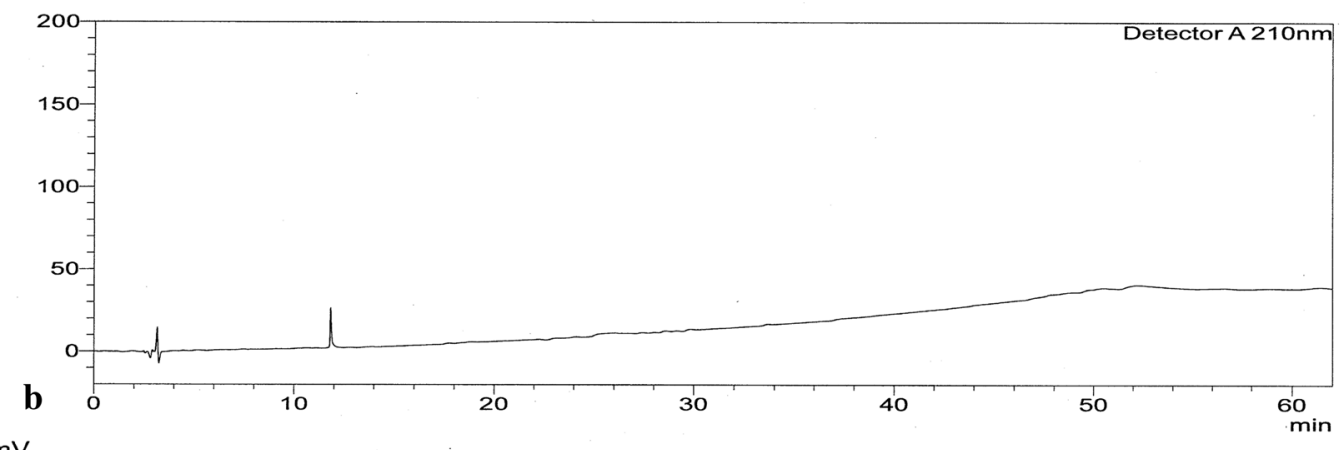

$\mathrm{mV}$

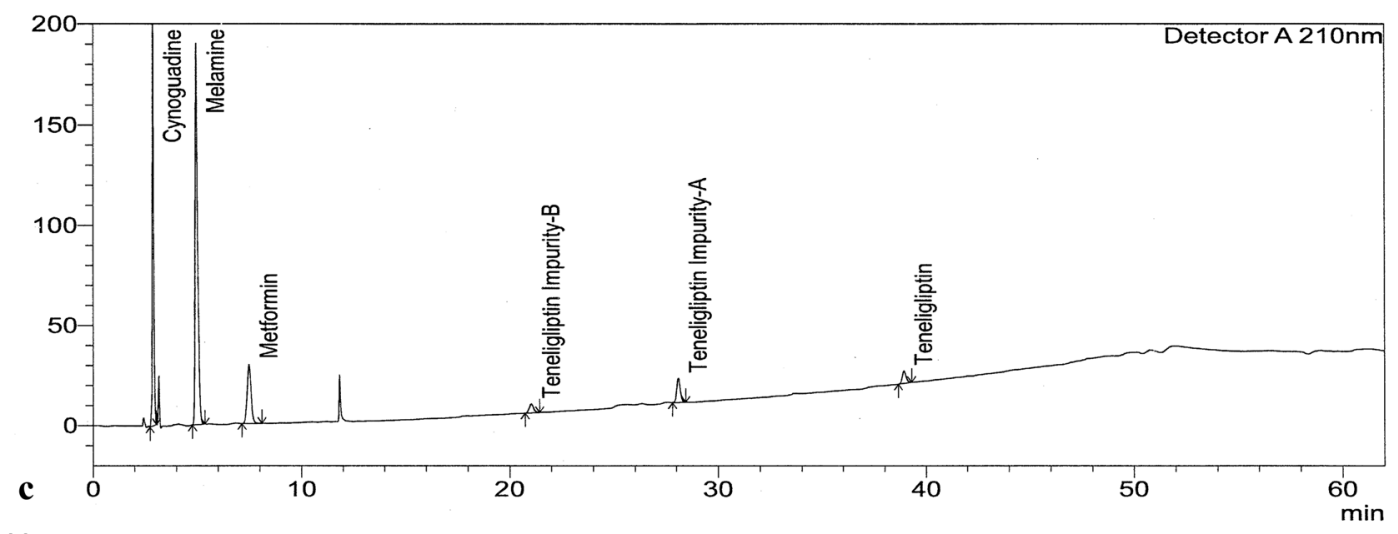

$\mathrm{mV}$

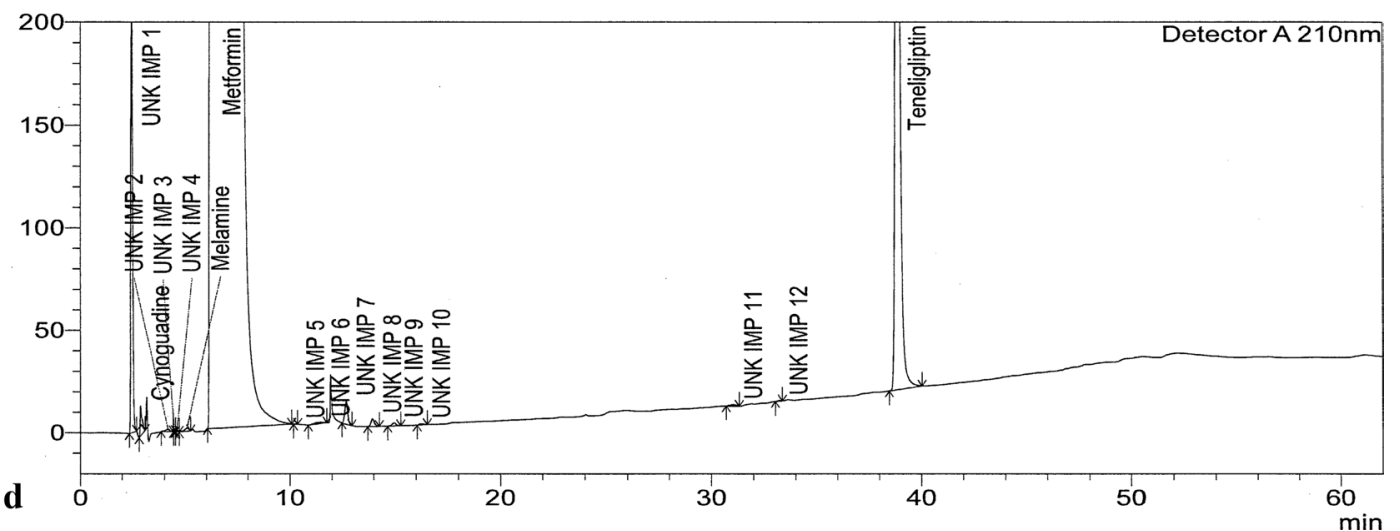

Fig. 2 a Representative chromatogram of blank solution. b Representative chromatogram of placebo solution. c Representative chromatogram of system suitability solution. $\mathbf{d}$ Representative chromatogram of sample solution 


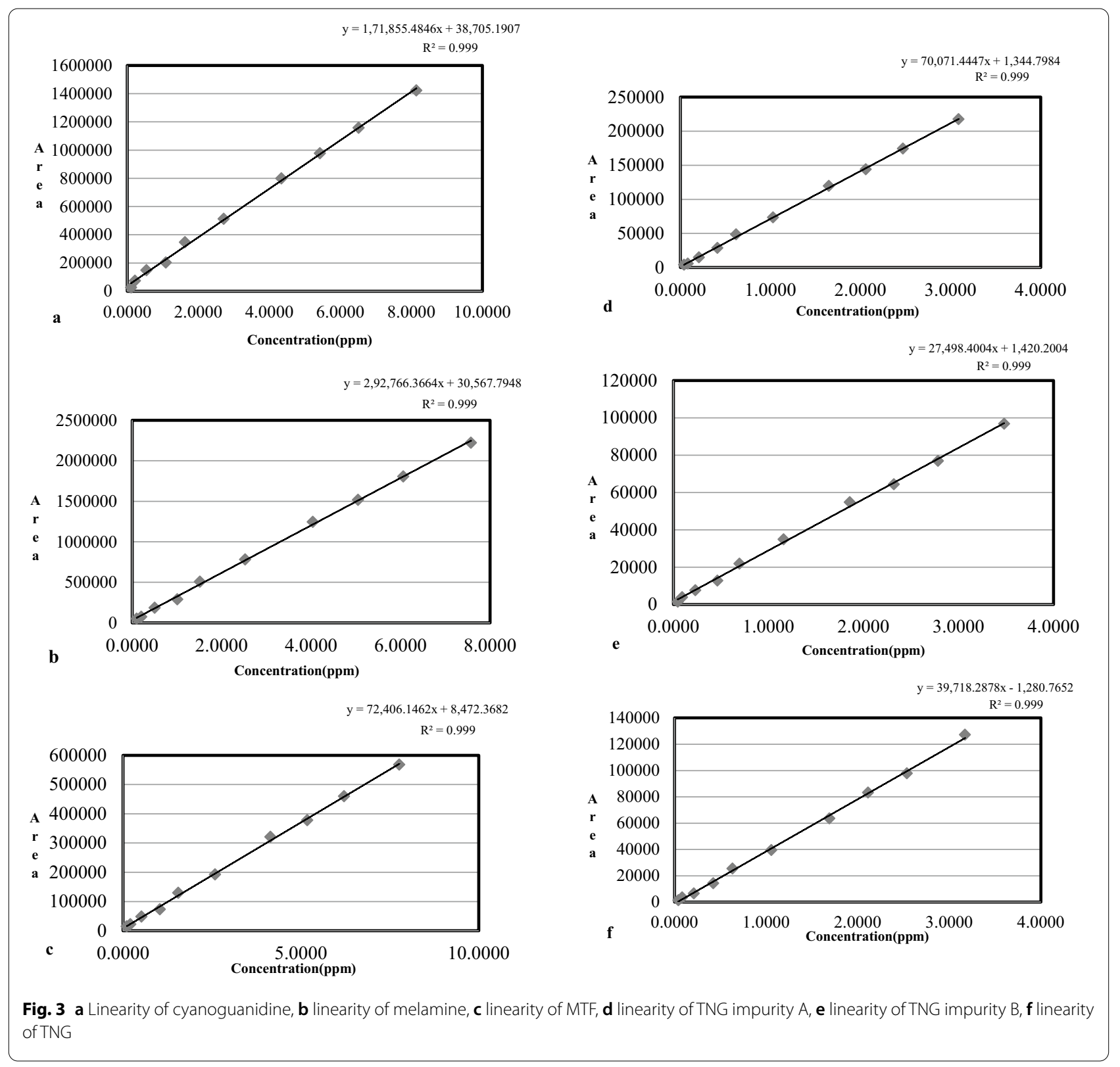

\section{Linearity and Range}

During the linearity study, we found that the area under the curve for each analyte peak and impurities was linear to the concentration. The correlation coefficients $\left(r^{2}\right)$ for all the peaks are reported (Fig. 3).

\section{Robustness}

During the robustness study, we observed that the system suitability parameters like RT, RRT and resolution were unaffected with small change in the $\mathrm{pH}$, detection wavelength, column temperature and flow rate. The developed method showed minor sensitivity toward the gradient composition change. The $5 \%$ change in the organic composition of the mobile phase altered the retention time of TNG peak by about $10 \%$ indicating this to be a critical method parameter.

\section{Discussion}

Precise, accurate and robust method was developed for impurity profiling of MTF and TNG in their combination tablet dosage form. At present, only assay method of MTF and TNG was reported individually or in combination with other drugs by various techniques like UV [6-8], HPTLC 
$[9,10]$ and HPLC [11-19]. Some individual method of degradation products of MTF and TNG was also reported [22-24], but at present no simultaneous impurity profiling method was reported for this combination drug product. The developed method was validated to meet the specification criteria for all validation parameters as per ICH guidelines Q2 (R). The method was found capable to quantitate the analytes and impurities from LOQ level to $150 \%$ of the impurity limits. The recovery for both analytes and impurities was found to be between 80 and 120\% at LOQ level and $85 \%$ to $115 \%$ at $50 \%$ to $150 \%$ level. Method is unaffected by deliberate changes in the method parameters during the robustness study. The standard and test solutions were stable up to $48 \mathrm{~h}$ at room temperature.

\section{Conclusions}

The result obtained from validation study implies that the developed method is precise, accurate, linear and robust. The method is applied for stability study of the formulation products and shows very precise and accurate results. Impurity isolation, detection, separation and quantitation are key parameters of any drug and drug products which determine the efficacy and safety of the medication. Because of high requirement of this combination in the market, we successfully separate the impurities of both the drugs in single method, so patient will get safe and effective medication. Hence, the proposed method is supportive to researchers for saving the development time and cost. No any hazardous chemicals were used in the analysis, and also, the method consumes fewer amounts of organic solvents; hence, the method is safe and eco-friendly. The developed method can be successfully used for the routine testing of impurities in pharmaceutical products during the commercial manufacturing of batches.

\section{Abbreviations \\ MTF: Metformin HCl; TNG: Teneligliptin hydrobromide hydrate; ICH: Interna- tional conference on harmonization; RP-HPLC: Reverse phase high-perfor- mance liquid chromatography; USP: United States pharmacopoeia; API: Active pharmaceutical ingredient; ODS: Octadecyl silane; SD: Standard deviation; RSD: Relative standard deviation; PPM: Parts per million; LOD: Limit of detec- tion; LOQ: Limit of quantitation; UNK IMP: Unknown impurity.; RH: Relative humidity; Imp.: Impurity; CYN: Cyanoguanidine.}

\section{Acknowledgements}

The authors wish to thank Mr. Vinod Ramchandra Jadhav, chairman and Mr. AvinaashMandale, MD Sava Healthcare Limited for their constant support and encouragement.Thanks are also due to Mr. Sachin Margaj for formatting the figures in this article.

\section{Authors' contributions}

All authors have equally contributed. All authors read and approved the final manuscript.

\section{Funding}

No external funding source for this work.
Availability of data and materials

All the data is available upon request.

\section{Declarations}

Ethics approval and consent to participate

Not applicable.

\section{Consent for publication}

Not applicable.

\section{Competing interests}

The authors declare that they have no competing interests

\section{Author details}

${ }^{1}$ Research Centre, Sava Healthcare Limited, Plot No. 17/6, D1Block, Chinchwad MIDC, Pune, Maharashtra 411019, India. ²Department of Chemistry, Shrikrishna Mahavidyalay Gunjoti, Gunjoti, Maharashtra 413606, India.

Received: 21 June 2021 Accepted: 7 October 2021

Published online: 28 October 2021

\section{References}

1. Kommineni V, Chowdary KPR, Prasad SVUM (2017) Development of a new stability indicating RP-HPLC method for simultaneous estimation of metformin hydrochloride and teneligliptin hydrobromide and its validation as per ICH guideline. Indo Am J Pharm Sci 4(05):1109-1119

2. http://www.uspbpep.com/ep50/Metformin\%20hydrochloride.pdf

3. https://pubchem.ncbi.nlm.nih.gov/compond/Teneligliptin-hydrobromi de-hydrate

4. Vasavi Devi D, Dugasani S, Gopireddy V (2018) Chemometric assisted method development for teneligliptin and metformin by stability indicating RP-HPLC technique and its validation. Asian J Chem 30(12):2704-2710

5. Chandana M, Rao M, Samrajyam B, Sireesha K, Premi V (2016) Analytical method and validation of Teneligliptin in pharmaceutical dosage form by RP-HPLC method. IJRDO 12(1):1-12

6. Sen A, Hinsu D, Sen D, Zanwar A, Maheshwari R, Chandrakar V (2016) Analytical method development and validation for simultaneous estimation of teneligliptin hydrobromide hydrate and metformin hydrochloride from its pharmaceutical dosage form by three different UV spectrophotometric methods. J Appl Pharm Sci 6(09):157-165

7. Mukthinuthalapati M, Sistla M, Naik R (2020) New validated spectrophotometric methods for the combined dosage form of Teneligliptin and Metformin. Res J Pharm Technol 13(1):270-274

8. Pathade P, Bairagi V, Ahire Y, Aher B (2019) Development and validation of stability indicating UV spectrophotometric method for estimation of Teneligliptin in bulk and tablet dosage form. Asian J Pharm Anal 9(3):3427-3435

9. Malani A, Kothapalli L, Bhimanwar R (2018) Development and validation of stability indicating High performance thin layer chromatographic method for simultaneous estimation of metformin hydrochloride and teneligliptin hydrobromide in combination dosage form. Int Res J Pharm 9(6):147-153

10. Patel M, Patel D, Shah U, Kachhiya H (2021) Simultaneous quantification of teneligliptin hydrobromide and metformin hydrochloride: an improved HPTLC method with implementation of Plackett-Burman design. J Chem Metrol 15:65-75

11. Vetapalem R, Yejella R, Atmakuri L (2020) Development and validation of a stability indicating RP-HPLC method for simultaneous estimation of Teneligliptin and Metformin Turk. J Pharm Sci 17(2):141-147

12. Patil D, Sufiyan A, Shastry V, Mujawar T, Thakare L (2017) Analytical method development and validation for the simultaneous estimation of Metformin and Teneligliptin by RP-HPLC in bulk and tablet dosage forms. J Pharm Res 11(6):676-681

13. Sunkara M, Mukthinuthalapati M (2018) Simultaneous determination of Metformin and Teneligliptin by liquid chromatography in tablets. Asian J Pharm 12(2):S736 
14. Swetha A, Kuber B (2018) A novel stability indicating liquid chromatography method for the simultaneous estimation of metformin and Teneligliptin in pure and pharmaceutical formulation. Int J Appl Pharm 10(5):274-280

15. Patil M, Bapna M, Shah P, Khoja S (2017) Development and validation of analytical method for estimation of metformin hydrochloride and teneligliptin hydrobromide hydrate in pharmaceutical dosage form. J Pharm Sci Biosci Res 7(2):200-208

16. Sharma A, Jain V, Prabhu V (2018) Stability-indicating RP HPLC method development and validation for simultaneous estimation of teneligliptin hydrobromide hydrate and metformin hydrochloride in combination tablet dosage form. Eur J Biomed Pharm 5(5):453-462

17. Patel V, Pandya C, Patel Z, Patel D, Pandya A (2021) Isocratic RP-UHPLC method development and validation of stability-indicating for simultaneous determination of teneligliptin and metformin in fixed-dose combination. Curr Chem Lett 10:503-516

18. Kommineni V, Chowdary KPR, Prasad SVUM (2017) Development of new stability indicating RP_HPLC method for simultaneous estimation of metformin hydrochloride and Canagliflozin and its validation as per $\mathrm{ICH}$ guideline. IJPSR 8:3427-3435

19. Prasad P, Satyanarayana K, Krishnamohan G (2015) Development and validation of a method for simultaneous determination of Metformin and Saxagliptin in a formulation by RP-HPLC. AIM 6(11):841-850

20. Sunitha P, Narayane R (2017) Development and validation of stability indicating ultra performance liquid chromatography method for the quantification of Teneligliptin, hydrobromide hydrate and characterisation of its degradation products by spectroscopic techniques. RJPBCS 8(2):2264-2281

21. Rimawi F (2009) Development and validation of an analytical method for metformin hydrochloride and its related compound (1-cyanoguanidine) in tablet formulations by HPLC-UV. Talenta 79(5):1368-1371
22. Reid I (2017) Development of normal phase high-performance liquid chromatographic method for determination of metformin and its related impurities in bulk material. J Pharm Innov 6(5):157-160

23. Gabriela K, Elzbieta A (2010) Determination of impurities in medical products containing metformin hydrochloride. Acta Pol Pharm 67(6):593-598

24. Sushant J, Sunil R, Kalyanaraman N, Popatrao B (2017) Development of RP-HPLC, Stability indicating method for degradation products of linagliptin in presence of metformin $\mathrm{HCl}$ by applying 2 level factorial design; and identification of impurity-VII, VIII and IX and synthesis of impurity-VII. Sci Pharm 85(3):2-17

25. Shraddha P, Gangadhar M, Rajendra J, Yatish B (2010) Simultaneous determination of Glimepiride and metformin hydrochloride impurities in sustained release pharmaceutical drug product by HPLC. Schizophr Res J 2(4):157-168

26. Maria A, Shereen M, Ehab E, Marwa F, Bassam A (2019) Analysis and bioanalysis of Omarigliptin, Trelagliptin and Alogliptin: applied to biological samples and degradation kinetic study. Microchem J 148:253-261

27. ICH-Q2A, (R1) (1995) Text on validation of analytical procedures. U.S. Department of Health and Human Services. USFDA, pp A1-A13

28. ICH-Q2B, (R1) (1996) Validation of analytical procedures, methodology. U. S. Department of Health and Human Services. USFDA, pp 1-10

\section{Publisher's Note}

Springer Nature remains neutral with regard to jurisdictional claims in published maps and institutional affiliations.

\section{Submit your manuscript to a SpringerOpen ${ }^{\circ}$ journal and benefit from:}

- Convenient online submission

- Rigorous peer review

- Open access: articles freely available online

- High visibility within the field

- Retaining the copyright to your article

Submit your next manuscript at $\boldsymbol{\nabla}$ springeropen.com 